\title{
Pull-out Behavior of Reinforcing tendons of Nehemiah Anchored Earth System
}

\author{
K. J. S. Munasinghe and R.D.D. Dayawansha
}

\begin{abstract}
The Nehemiah anchored earth wall system is a type of mechanically stabilized backfill structure where the mode of stress transfer from the backfill to the reinforcement is by passive resistance in addition to the friction. This paper presents the findings of pull out resistance of the reinforcing tendon together with the anchor block of the anchored earth wall system. Nine experimental tests were carried out to demonstrate the factor of safety of the pull out resistance of the anchored earth wall. In addition, a summarized historical background, design concepts, construction procedures and performance of the Nehemiah anchored earth wall system is provided.
\end{abstract}

Keywords: $\quad$ Nehemiah Anchored Earth Wall System, Design, Construction, Pull out Behavior

\section{Introduction}

The Nehemiah anchored earth wall system was first developed and introduced in Malaysia in 1993. The system has been used all over Malaysia and it is now being implemented in countries like Singapore, India, Bangladesh and Sri Lanka. This system has been used as part of the bridge abutment that retains embankment soil on the Southern Transport Development Project.

The Nehemiah anchored earth wall is a type of reinforced soil wall system, which is reinforced by galvanized steel bars and anchored by precast concrete blocks. The facing is vertical consisting of modular hexagonal shaped concrete panels interlocked together. The mode of stress transfer from the backfill to the reinforcement is by passive resistance in addition to friction.

The system is ideal for urban highway interchanges, railway embankments, bridge abutments, housing retaining walls, marine walls, river walls, secondary containment dykes and military walls.

The advantages of such a system are cost effectiveness, technical feasibility, rapid and easy installation, minimum supervision requirements, aesthetically pleasing appearance, environmental friendliness, flexibility and durability (Life span extending up to 120 years).

\section{The Anchored Earth System}

The anchored earth system consists of three major components namely the facing panels, the reinforcing tendons and the anchor blocks.
A schematic representation of the embodiment of the anchored earth system is shown in Figure 1.

\subsection{Facing Panels}

The facing panels are hexagonal shaped and are made of precast concrete (grade 30/20) as shown in Figure 2. They are interlocked with dowel bars with tolerance for horizontal moments. The horizontal joint between the panels are inserted with compressible material to allow for vertical moments. As such the facing is flexible and can tolerate large differential settlement.

\subsection{Reinforcing Tendons}

The reinforcing tendons are made of carbon steel rods in compliance with BS 8006: 1994 code of practice for strengthened/reinforced soil and other fills. The tendons are hot-dipped galvanized to prevent corrosion. The advantage of using round bars instead of strips is the greater durability against corrosion in view of the reduced surface area exposed. The tendons are connected to the facing panels by nuts with the threaded end coated with epoxy.

\subsection{Anchor Blocks}

The anchor blocks are discrete precast concrete blocks which act as a deadman. 
A hole is preformed in the centre of the block to enable the tendon to pass through, thereby connected with a nut and washer.

A typical arrangement is shown in Figure 3. The advantage of using anchor blocks is that it enhances the pull out resistance of the reinforcing tendons. As a result, the use of cohesive frictional material for backfill is possible since the system does not rely so much on friction for the stress transfer.

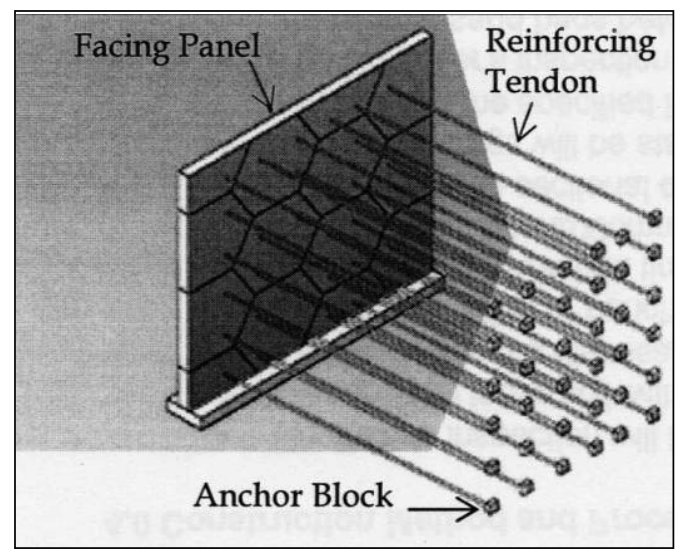

Figure 1 -- Schematic Representation of Nehemiah Anchored Earth Wall System

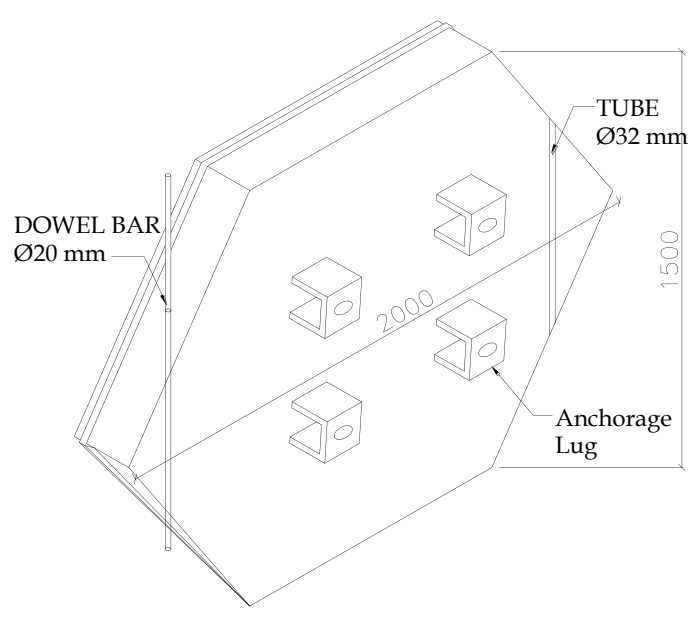

Figure 2 - Hexagonal Shaped Facing Panel of Nehemiah Anchored Earth Wall System

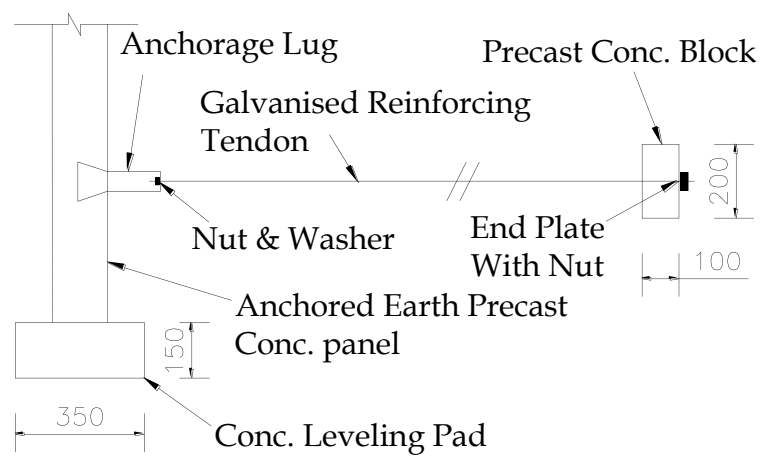

Figure 3 - Typical Arrangement of Facing Panel, Reinforcing Tendon and Anchor Block

\section{Design of Anchored Earth Wall System}

The Nehemiah wall is a type of reinforced earth system. It is governed by the combination of earth reinforcement and deadman anchorage technology. It uses locally available material such as steel bars and concrete. The design is based on the BS 8006: 1995 code of practice or AASHTO LRDF bridge design specifications for strengthened/reinforced soil and other fills. The typical design cross section of the wall is shown in Figures 4 and Figure 5. The design of the Nehemiah wall involves the external stability analysis and internal stability analysis.

Well Compacted Granular Fill for Nehemiah Reinforced Soil

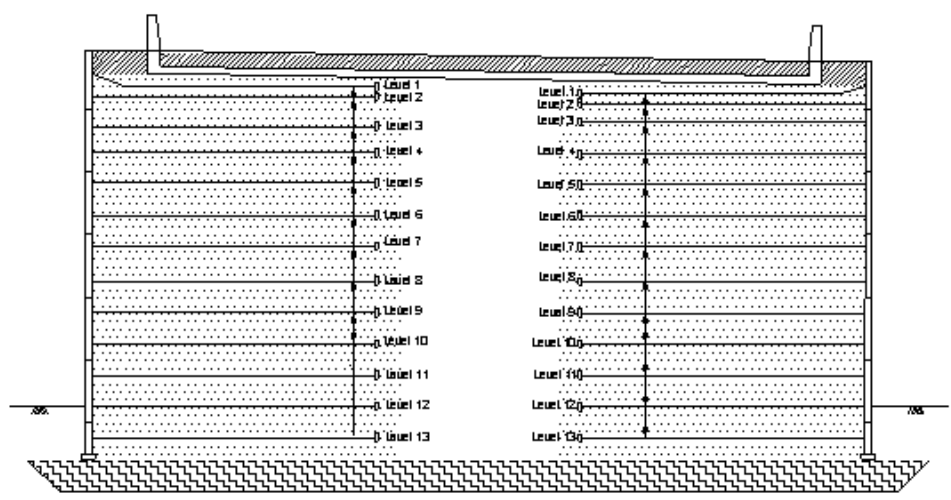

Figure 4 -Typical Transverse Section of Anchored Earth Wall System

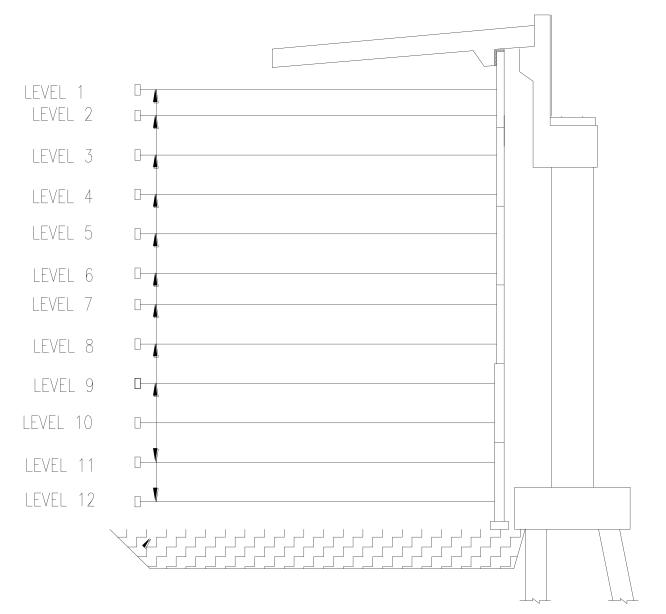

Figure 5 - Typical longitudinal Section of Anchored Earth Wall System for Bridge Abutment

\subsection{External Stability}

For the external stability analysis, the Nehemiah wall is analyzed as a gravity block. The factors of safety against sliding, 
overturning and bearing are checked; designed to ensure that they are adequate. The global analysis and the geotechnical analysis are also external stability analysis. They are not described in this paper.

\subsection{Internal Stability}

The internal stability analysis involves checks to ensure that the factors of safety against tensile strength and pull out failure of all the reinforcing tendons are adequate.

\subsubsection{Tensile Failure}

In the design, it is important that the number and size of the reinforcing tendons are adequately provided so that the tension developed in the tendons is always less than the allowable tensile strength of all the tendons.

The tensions in the reinforcing tendons [4] are computed as follows:

$T i=K S_{V} \sigma_{V}$

Where,

$T_{i}=$ Tension developed in the reinforcing tendon at $\mathrm{i}^{\text {th }}$ levels

$K=$ Coefficient of earth pressure within the reinforced block

$S_{v}=$ Vertical spacing of the tendons

$\sigma_{v}=$ Vertical stress acting on the $\mathrm{i}^{\text {th }}$ level of the tendons according to the Meyerhof pressure distribution

\subsubsection{Pull out Failure}

The ultimate pull out resistance of the reinforcing tendons is the sum of the shaft frictional resistance and the anchor capacity of the anchor block. The shaft resistance is determined by the friction developed between the backfill and the effective length of the tendon [7] Which is shown in Figure 6.

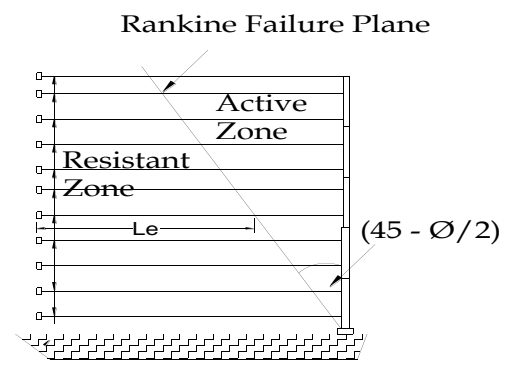

Figure 6 - Effective Length of Reinforcing Tendons - Le
The shaft resistance is computed as follows:

$F_{S}=\mu \tan \theta d L_{e} \sigma_{V}$

Where,

Fs $=$ Shaft resistance

$\mu=$ Coefficient of friction

$\varnothing=$ Angle of Internal friction of the backfill

$\mathrm{d}=$ Diameter of the tendon

$\mathrm{L}_{\mathrm{e}}=$ Effective shaft length

The anchor capacity [7] is computed as follows:

$P_{a}=4 K_{p} h w \sigma_{v}$

Where,

$\mathrm{P}_{\mathrm{a}}=$ Passive resistance of the backfill in front of the anchor block

$\mathrm{K}_{\mathrm{p}}=$ Coefficient of passive earth pressure

$\mathrm{h}=$ Height of the anchor block

$\mathrm{w}=$ Width of the anchor block

Hence, the total pull out resistance is given as follows:

$P_{r}=F_{S}+P_{a}$

The factor of safety for pull out resistance must be larger than or equal to unity. It is computed as follows. FOS for Pull out Resis tan ce $=\frac{\theta \operatorname{Pr}}{T_{\text {design }}}$..(5)
Where, $\operatorname{Pr}=$ Ultimate pull out resistance

$\varnothing=$ Resistance factor for pull out resistance, which can be take as 0.9

$\mathrm{T}_{\text {design }}=$ Design working load

\section{Construction of Nehemiah Anchored Earth Wall System}

The construction sequence shall start with site preparation before wall construction. It is explained under the following headings.

\subsection{Site Preparation}

The first step in the construction was to remove the unsuitable subsoil material or any weak material with debris and replace it with compacted granular material. Once the sub soil was strengthened, the leveling pad was cast at base level. Unreinforced grade 20/20 concrete was used. After the site preparation was completed, the wall erection can be commenced. 


\subsection{Wall Erection}

The facing panels are hoisted with the aid of a lifting device and placed on the leveling pad. The panels are supported with temporary props and wooden clamps. The granular material is then backfilled, spread, leveled and compacted to the first tendon level. The reinforcing tendons are then connected to the facing panels and the anchor blocks. This process of installing panels, backfill, tendons and anchor blocks is repeated until the full height of the wall is reached. Sponge was used as joint material in all the joints between the panels when placing the panels.

\subsection{Backfilling}

The backfilling operation is carried out immediately following the completion of the installation of each row of the panels. 0-40 $\mathrm{mm}$ mixed granular fill materials are compacted in layer thickness not exceeding $375 \mathrm{~mm}$ so that each reinforcing bar can be fixed at the required level on top of the compacted fill material without any voids forming directly underneath the reinforcing bars. The direction of travel of the construction vehicle for the placement, spreading and compaction of the fill is parallel to the alignment of the wall at all times. Sharp turns of the vehicle or moment perpendicular to the wall causing centrifugal forces exerting toward the rear face of the panel shall be strictly avoided. Heavy vehicles weighing more than $1000 \mathrm{Kg}$ shall not be allowed within the $1.5 \mathrm{~m}$ zone from the rear face of the panel.
The backfill material is compacted to $95 \%$ of the maximum dry density as determined in accordance with BS 1377: 1975. During the backfilling operation and compaction, heavy compaction vehicles should be kept back at least $1.5 \mathrm{~m}$ away from the back face of the facing panel. This $1.5 \mathrm{~m}$ zone was compacted with a 1.0 ton vibratory plate compactor.

\section{Experimental Tests}

\subsection{Experiment Pull out Test}

The experiment was carried out in order to determine the pull out resistance of the reinforcing tendon together with the anchor block of the anchored earth wall. The vertical facing consisted of modular hexagonal shaped precast concrete panels interlocked to each other. Before erection of each panel, a hole of relevant tendon diameter was constructed in the center of the anchored earth facing panel. During the erection of the anchored earth wall, an extra reinforcing tendon with anchor block was installed with the free end jutting out by about $50 \mathrm{~mm}$ through the preformed hole in the panel to be installed at the desired location. The pull out test was carried out after the wall erection was completed. Figure 7 shows a view of the experimental wall with the reinforcing tendon diameter and the anchor block size.

A pull out cage was placed at the level of the test specimen tendon. The steel bracket and cage was then connected to the threaded end of the tendon test specimen.

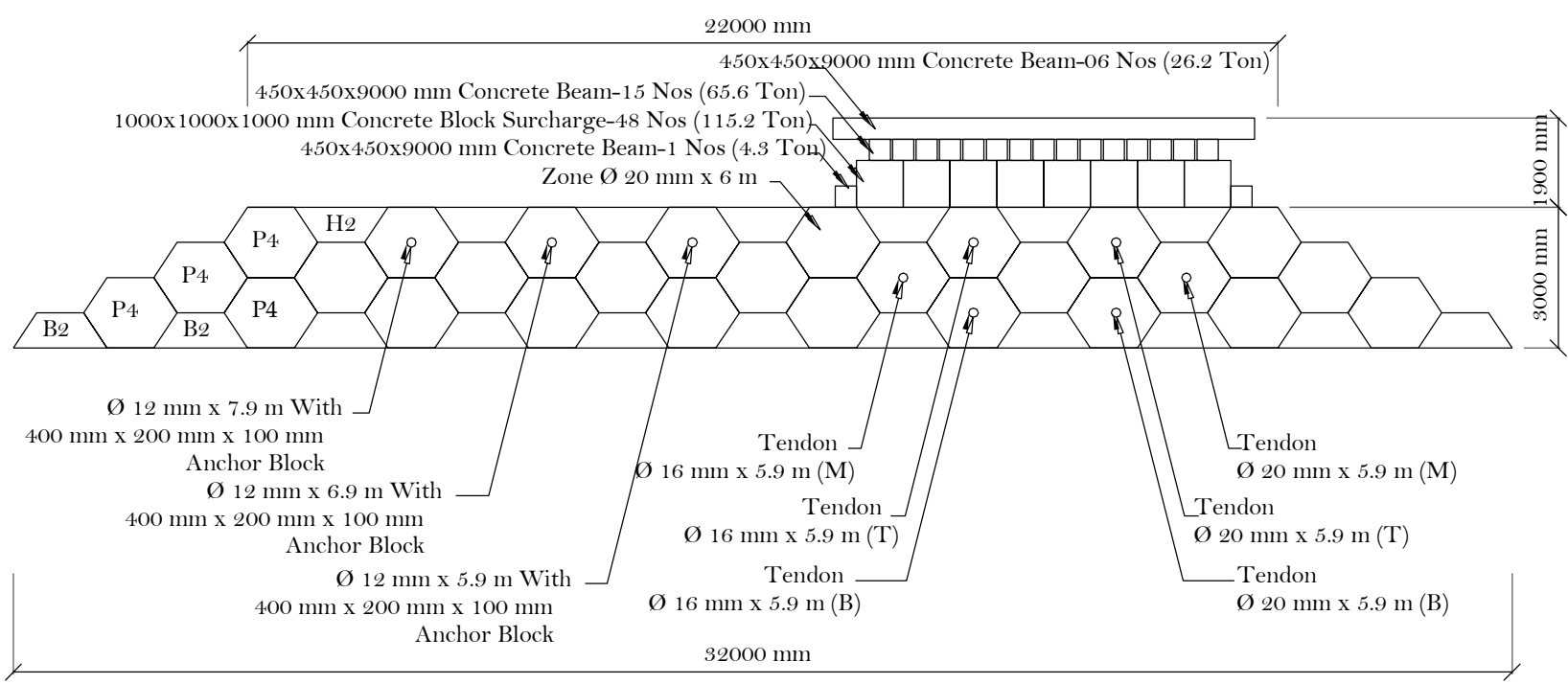

Figure 7 - View of the Experimental Wall 
Table 1 - Factors of safety for ultimate pull out resistance

\begin{tabular}{|c|c|c|c|c|c|c|}
\hline \multirow[t]{2}{*}{ Reinforcing Bars } & \multicolumn{2}{|c|}{$\begin{array}{l}\text { Design Working } \\
\text { Load, } \mathrm{T}_{\text {design }}(\mathrm{KN})\end{array}$} & \multirow{2}{*}{$\begin{array}{c}\text { Estimated } \\
\text { Pullout Force } \\
(\mathrm{KN})\end{array}$} & \multirow{2}{*}{$\begin{array}{l}\text { Pullout } \\
\text { Force, Pr } \\
\text { (KN) }\end{array}$} & \multicolumn{2}{|c|}{$\begin{array}{l}\text { Factor of Safety for } \\
\text { Pullout Resistance }\end{array}$} \\
\hline & ULS & SLS & & & ULS & SLS \\
\hline$\varnothing 12 \mathrm{~mm} \times 5.9 \mathrm{~m}$ & 16.19 & 11.99 & 19.62 & 46.31 & 2.57 & 3.48 \\
\hline$\varnothing 12 \mathrm{~mm} \times 6.9 \mathrm{~m}$ & 16.17 & 11.98 & 20.22 & 43.15 & 2.40 & 3.24 \\
\hline$\varnothing 12 \mathrm{~mm} \times 7.9 \mathrm{~m}$ & 16.16 & 11.97 & 23.14 & 45.78 & 2.55 & 3.44 \\
\hline$\varnothing 16 \mathrm{~mm} \times 5.9 \mathrm{~m} \mathrm{~T}$ & 30.64 & 22.69 & 44.39 & 75.78 & 2.23 & 3.01 \\
\hline$\varnothing 16 \mathrm{~mm} \times 5.9 \mathrm{~m} \mathrm{M}$ & 33.87 & 25.09 & 54.97 & 78.94 & 2.10 & 2.83 \\
\hline$\varnothing 16 \mathrm{~mm} \times 5.9 \mathrm{~m} \mathrm{~B}$ & 36.35 & 26.93 & 65.02 & 77.89 & 1.93 & 2.60 \\
\hline$\varnothing 20 \mathrm{~mm} \times 5.9 \mathrm{~m} \mathrm{~T}$ & 30.64 & 22.69 & 47.08 & 69.47 & 2.04 & 2.76 \\
\hline$\varnothing 20 \mathrm{~mm} \times 5.9 \mathrm{~m} \mathrm{M}$ & 33.87 & 25.09 & 58.23 & 103.15 & 2.74 & 3.70 \\
\hline$\varnothing 20 \mathrm{~mm} \times 5.9 \mathrm{~m} \mathrm{~B}$ & 36.35 & 26.93 & 68.71 & 99.46 & 2.46 & 3.32 \\
\hline
\end{tabular}

The pressure value of the hydraulic jack was then completely released before being fixed to the steel cage. The pressure gauge meter was set to indicate a zero reading. The hand pump was then gradually applied to tighten the gaps between the connections. The preliminary displacement was recorded as initial close up gaps.

The pressure in the hydraulic jack was gradually increased by manually working on the hand pump. As the pressure increased, the tendon was tensioned. The reading on the pressure gauge was recorded for each tendon displacement of $0.5 \mathrm{~mm}$ as measured by the dial gauge. The tendon was normally tensioned until one and a half times the designed tension capacity of the tendons.

\subsection{Results of the Analysis and Discussion}

The pull out force vs displacement of the anchored reinforcing bars are shown in Figures 8, 9 and 10 for various sizes of anchor bars with different lengths at various positions of the experimental wall. It was observed that the higher the diameter of the tendons the higher will be the pull out resistance, and the lesser the diameter of the tendon the lesser will be the pull out resistance. As well as the larger the diameter of the tendon the lesser the displacement, and the smaller the diameter of the tendon higher the displacement for a given force. The reason for this is larger the diameter the higher the shaft resistance, and smaller the diameter the lesser the shaft resistance of the reinforcing tendons. However comparing graphs the displacement at tested reinforcing bars were recorded and observed to be very small.

Further, comparing load against displacement behavior of same diameter anchors with same length at different levels, anchors at deeper elevations show higher pullout resistance. Similarly comparing equal diameter anchors at same level with different lengths, the longer anchors show higher estimated pullout force. Since experimental setup has been carried out only with $1 \mathrm{~m}$ difference of lengths these aspects can not be clearly distinguished with results achieved.

The field pull out test was carried out to measure the apparent pull out resistance of the anchored reinforcing tendons. The factors of safety for pull out resistance under ultimate and serviceability limit state for all the tested reinforcing bars are tabulated as shown on Table 1 and 2. The tables demonstrate the factors of safety for the pull out resistance under ultimate and serviceability limit state for all the tested reinforcing bars and the result was greater than one.

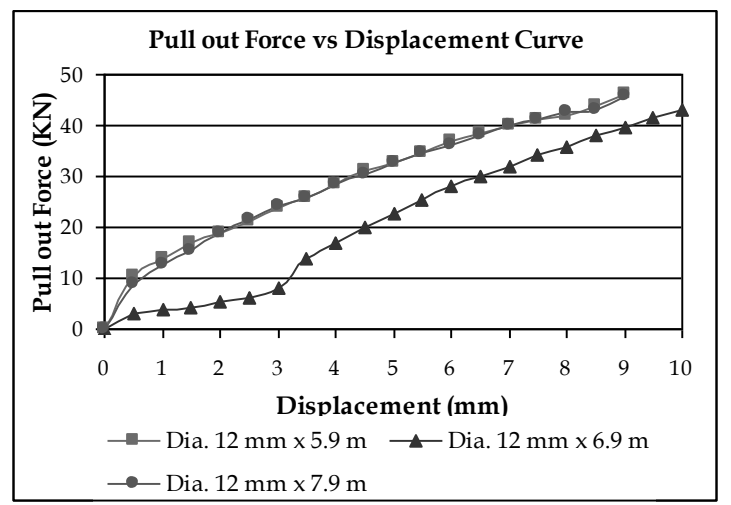

Figure 8 - Pull out Force vs Displacement Curve for $12 \mathrm{~mm}$ Tendons 


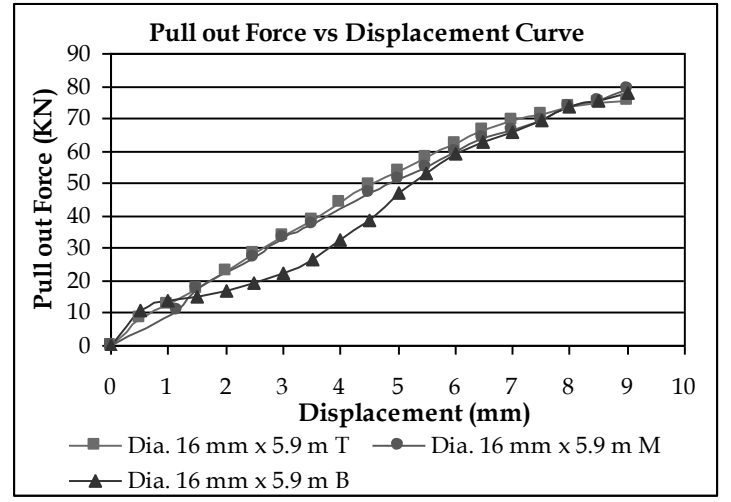

Figure 9 - Pull out Force vs Displacement Curve for $16 \mathrm{~mm}$ Tendons

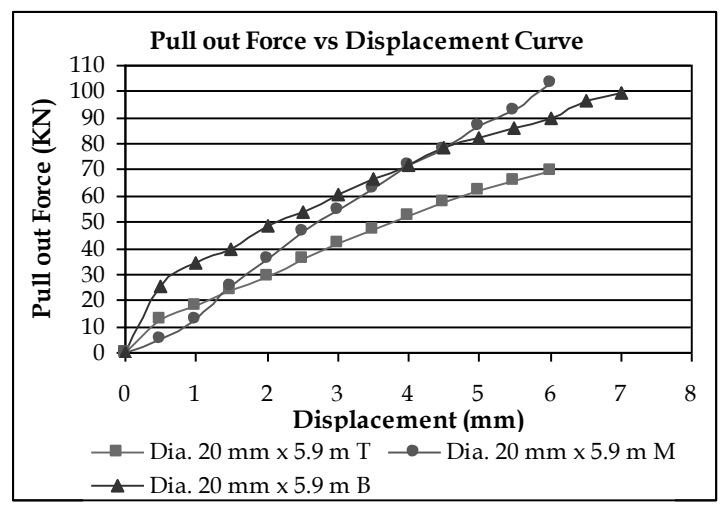

Figure 10 - Pull out Force vs Displacement Curve for $20 \mathrm{~mm}$ Tendons

\section{Conclusion}

1. Nehemiah anchored earth system can be effectively used in road embankments with higher factors of safety for pull out resistance under ultimate and serviceability limit state.

2. The larger the diameter of the tendons the higher the pull out force and smaller the diameter of the tendons the lesser the pull out force.

3. The larger the diameter of the tendons the lesser the displacement and the smaller the diameter of the tendon the higher the displacement.

4. The tested reinforcing bar displacements were recorded and were observed to be very small.

5. Factors of safety values given in the Table 1 may not be the maximum, because anchors were not loaded upto ultimate failure, specially in the case of the larger diameter anchors. Hence, it can be concluded that FOS is more than or equal to values given in Table 1 .

\section{Acknowledgement}

The authors would like to convey their heartfelt gratitude to Road Development Authority for providing background to carryout investigation in this important technical area. Further special mention is made of Roughton International and Kumagai Gumi Company Limited for their involvement in this work.

Our special gratitude is extended to Eng. Graham Fary (Senior Resident Engineer) who gave valuable suggestions while preparing this article and to Mrs. Lasanthi Wickramasinghe who supported in the word processing.

\section{References}

1. BS 5400 part 2, Steel, "Concrete and Composite Bridge", British Standard Institution, London, 1990.

2. BS 8006, Code of practice for Strengthened/Reinforced Soils and Other Fills', British Standard Institution, London, 1994.

3. BS 1377, “Soils for Civil Engineering Purposes", British Standard Institution, London.

4. Lee, C. H. and Oh, Y. C., "Design, Construction and Performance of an Anchored Earth Wall in Malaysia", Mechanically Stabilized Backfill, Wu(ed) Balkema, Rotterdam, ISBN 9054109025, 1997.

5. Faisal, Hi Ali, Bujang, B. K., Huat and Lee Chee Hai, "Influence of Boundary Conditions on the Behavior of an Anchored Reinforced Earth Wall" American Journal of Environmental Sciences, 2008, PP 289-296, ISSN 1553-345X.

6. Faisal, Hi Ali, Bujang, B. K., Huat and Lee Chee Hai, "Field Behavior of High Anchored Reinforced Earth Wall" American Journal of Environmental Sciences, , 2008, PP 297-302, ISSN 1553-345X.

7. Lee Chee hai, Nilaweera, Nimal S. , "Design and Construction of a $20.5 \mathrm{~m}$ High Innovative Nehemiah Wall Near Cameron Highland, Pahang" Nehemiah Reinforced Soil Sdn Bhd, Malaysia.

8. Chin Tat Hing and Jason Khor Lee Chong, "Repair of Road Embankment Failure using Reinforced Soil Wall" Nehemiah Reinforced Soil Sdn Bhd, Malaysia.

9. Joel Lim, "Overcoming Construction Challenges of Time Constraint - A Case Study of Kuantan Interchange Project" Nehemiah Reinforced Soil Sdn Bhd, Malaysia. 